\title{
NIETZSCHE E A INSPIRAÇÃO POÉTICA: A OSCILAÇÃO ENTRE OS MODELOS DE PLATÃO E ARISTÓTELES
}

\author{
Maicon Engler \\ Unicentro/Guarapuava
}

\begin{abstract}
Resumo: 0 presente artigo escrutina dois momentos da obra de Nietzsche em que ele se detém sobre 0 fenômeno da inspiração poética, com o fito de ressaltar suas diferenças e de mostrar como cada um deles é reminiscente das reflexões de Platão e Aristóteles sobre esse tema. No primeiro caso, comenta dois parágrafos do livro Humano, demasiado humano, salientando como Nietzsche desenvolve neste caso visão secular e psicofisiológica da inspiração, a qual relembra várias reflexões de Aristóteles. No segundo, examina o que ele escreve no Ecce Homo sobre sua inspiração ao compor o Zaratustra, argumentando que ele avança então perspectiva divina da inspiração, a qual recorda, por sua vez, vários traços da Inspirationslehre de Platão. Como conclusão, elaboram-se alguns pensamentos baseados em Pierre Hadot sobre a transmissão da filosofia através do conceito retórico de tópos.
\end{abstract}

Palavras-chaves: Nietzsche; inspiração; poesia; Platão; Aristóteles.

\begin{abstract}
I analyze in this paper two moments of Nietzsche's works where he discusses poetic inspiration in order to point out the differences between them and to show how they are reminiscent of both Plato's and Aristotle's reflections on this subject. In the first case, I comment on two paragraphs of Human, all too human, and show how Nietzsche develops in this case a secular and psychophysiological view of inspiration that is reminiscent of many ideas of Aristotle. In the second case, I study what Nietzsche says in Ecce Homo about his own inspiration in writing Zarathustra and argue that he then puts forward a divine perspective of inspiration that reminds many traces of Plato's Inspirationslehre. By way of conclusion I elaborate on some thoughts of Pierre Hadot about the transmission of philosophy through the rhetorical concept of tópos.
\end{abstract}

Keywords: Nietzsche; inspiration; poetry; Plato; Aristotle.

Natura fieret laudabile carmen an arte, quaesitum est; ego nec studium sine diuite uena nec rude quid prosit uideo ingenium; alterius sic altera poscit opem res et coniurat amice ${ }^{1}$. (Horácio, Ars Poetica, p. 408-409)

\section{Introdução}

Do início ao fim de sua carreira consagra-se Nietzsche, simultaneamente, à reflexão sobre a Antiguidade Clássica (Altertum) e sobre a

\footnotetext{
1 "Tem-se perguntado se um poema se torna digno de louvor pela arte ou pela natureza. Eu não vejo de que serve o trabalho sem uma veia fértil, nem de que serve o engenho rude, assim uma coisa reclama 0 auxílio da outra e conspiram amigavelmente".
} 
arte. Seu romântico livro de estreia e suas preleções universitárias já reúnem ambos os interesses e inauguram uma agenda de pensamento que será desenvolvida, em diferentes graus, em todas as obras vindouras. De fato, não há sequer um livro em que ele deixe de discutir o significado filosófico da civilização greco-romana ou de comentar as posições dos pensadores desse período. Temas como o estilo dos autores que mais lhe apraziam, como Tucídides e Salústio (NIETZSCHE, 2002, p.154-155), até a necessidade de superar a civilização helênica, na esteira dos múltiplos projetos já aventados no Idealismo alemão, são debatidos em aforismos e pequenos parágrafos que demonstram como o estudo da filologia clássica sempre permaneceu ativo em seu horizonte teórico. Sua formação no seio da florescente e respeitada filologia alemã, que contava com contemporâneos da alçada de Burckhardt, Willamowitz, Mommsen e Bernays, é fulcral para o entendimento de muitas das ideias mais filosóficas que ele defende posteriormente. Isso pode ser comprovado de várias maneiras. Por exemplo, por meio das etimologias de que Nietzsche se vale para embasar sua versão da genealogia da moral, que assentam em acurado conhecimento das línguas clássicas, em especial do grego (NIETZSCHE, 1999, p.263-264); ou por meio de sua descrição da filosofia de Heráclito, descrição essa que já contém em crisálida doutrinas que hão de tornar-se caras ao filósofo alemão, como a ideia da gratuidade do devir intuída pelo homem estético (NIETZSCHE, 1988, p.830-831).

Do mesmo modo, a questão da arte é recorrente em sua obra. Ela varia desde discussões de ideais estéticos e autores, como o romantismo, o romance psicológico de Dostoievsky ou a música de Wagner, até a criação de uma obra artística, o Zaratustra, a qual resume, em uma forma literária similar aos grandes livros das religiões reveladas, suas posições filosóficas mais características. Noutras palavras, Nietzsche não apenas fez o trabalho de intérprete dos grandes problemas filosóficos relativos à obra de arte, tal como um especialista em estética faria, como também se esforçou por criar ele mesmo, seja no Zaratustra, seja no aperfeiçoamento do estilo aforismático advindo da tradição moralista francesa e do romantismo alemão, uma obra que é a um só tempo teórica e artística. Esta junção de filosofia e arte tornou ambígua a recepção de seu pensamento. Por um lado, ela desagradou e continua a desagradar os filósofos profissionais mais "sérios", que nutrem preferência velada pela forma do sistema e por uma escrita supostamente objetiva, tal como representada pela hodierna academia. Para esses filósofos, Nietzsche é um escritor talentoso que expressou certa atitude perante a vida (Lebenseinstellung) por meio de uma obra que não pertence propriamente ao domínio da teoria, mas antes ao domínio da arte (CARNAP, 2009, p.308). Por outro lado, seu uso bem-sucedido de formas literárias facilitou a absorção de 
suas ideias e continua a atrair grande público de artistas e de leitores comuns fora da academia. A maioria das pessoas que lê Nietzsche não sabe explicar a relação da morte de Deus com o fim da metafísica e o significado desse evento no interior da história da filosofia, algo que é objeto de amplo estudo de Heidegger, por exemplo. Elas tampouco sabem que a insistência do filósofo alemão na fidelidade ao mundo sensível representa, como insiste Hannah Arendt (ARENDT, 1972, p.57), uma inversão da tradição filosófica iniciada por Platão. Todavia, elas entendem que a bela história do homem louco que procura por Deus, bem como a equiparação entre platonismo e cristianismo e o consequente repúdio de uma realidade no Além (Jenseits) refletem uma das posições filosóficas centrais do filósofo alemão - e isso basta para que o leiam e apreciem. Controvérsias à parte, é um fato que Nietzsche é mais um dos filósofos que não vê a escolha do estilo como algo neutro ou simplesmente dado, senão que, como outros pensadores com pendores artísticos Kierkegaard ou Platão, por exemplo - compreende o teor de determinada posição teórica, a Stimmung de certa filosofia, em conjunto com a forma como ela é exprimida. Há em sua obra, em resumo, uma filosofia do estilo implícita².

Neste horizonte duplo de preocupações filológicas e estéticas, não poderia faltar o tema da inspiração poética. Em primeiro lugar, porque ele representa uma das mais antigas teorias da arte, a qual deve ser estudada, junto com o conceito de mimese, por qualquer erudito interessado nas intuições estéticas greco-romanas. E, em segundo lugar, porque ela ainda vigorava naquela que foi a principal resposta moderna para o problema da criação artística: a Genieästhetik. Na Antiguidade, a inspiração foi tratada por autores eminentes como Homero, Hesíodo, Demócrito, Platão, Aristóteles, Cícero Horácio, Longino etc. Desde o influente legado épico até a reflexão tardia da Segunda Sofística, passando pela absorção da cultura grega realizada pela intelligentsia romana, conferia-se-lhe papel-chave nos tratados dedicados à arte. A essa questão aliava a antiga poética outros problemas não menos relevantes, como o talento natural (euphuía), o entusiasmo (enthousiasmós), a participação dos deuses na criação artística (theîa moîra), a relação entre natureza (phýsis) e arte (téchnè), entre loucura (manía) e vinho etc. Quando esta teoria é compreendida em toda a sua abrangência - algo que infelizmente ainda não foi concretizado, dado que ela tenha sido ofuscada por uma fixação nem sempre sadia no problema da mimese ${ }^{3}$ - percebe-se, do mesmo modo, que ela está por

\footnotetext{
2 Para um comentário sobre a relação intrínseca entre filosofia, arte e estilo, cf. WEINECK, 2002. Para o caso de Platão: NUSSBAUM, 2009; MICHELINI, 2003.

3 Para uma análise detalhada desse problema: ENGLER, 2016, cap.III. Retomar a importância da doutrina da inspiração na Antiguidade significa, pois, levar a sério o ĺon. Sobre isso, conferir os trabalhos clássicos de VERDENNIUS, 1943; 1944 e FLASHAR, 1958.
} 
detrás da ideia moderna do gênio. $O$ fato de o artista genial não saber responder como compõe suas obras, nem ser capaz de reduzi-las a regras práticas ou aos preceitos gerais de um Dichtkunst - ponto fundamental, como se sabe, na teoria estética de Kant (KANT, 2001, \$47) - é uma ideia que remonta ao antigo debate em torno da inspiração. E ela não está sozinha. Outros elementos indispensáveis do conceito de gênio - a passividade do artista, a infalibilidade de sua inspiração, o caráter impessoal dos conteúdos que recebe etc. - têm sua origem no quadro conceitual antigo, como já notaram alguns estudiosos (JANAWAY, 1992; WOOLF, 1997).

Ao que parece, esses fatos fazem com que a inspiração seja também tratada por Nietzsche. Contudo, o modo como ele o faz está longe da sistematicidade. Há, com efeito, uma clara oscilação em sua abordagem, a qual se deixa ver nitidamente em duas ocasiões: na seção sobre a arte do Humano, demasiado humano e no Ecce Homo. Na primeira obra, Nietzsche propõe versão secular da inspiração, que não recorre à participação dos deuses e que deslinda a criação artística por meio de faculdades psicológicas. Consoante o tom fundamental da obra em apreço, ele vê na inspiração algo humano, demasiado humano. Na segunda ocasião, ao refletir sobre o Zaratustra, ele se permite alguns laivos de superstição e fala em revelação (Offenbarung), no sentido religioso, evocando em seguida a completa passividade do artista e, a fortiori, o fato de ele não pode ser a verdadeira origem das ideias que recebe. Não obstante queira evitar a ligação da sua obra com qualquer tipo de culto religioso, Nietzsche não deixa dúvidas de que o Zaratustra foi concebido em estado de graça, por assim dizer, como se tivesse sido ditado por algo ou alguém. A oscilação, destarte, salta aos olhos de qualquer leitor atento. Mais do que isso, ela sugere outro dado importante, pelo menos para aqueles que estão familiarizados com o tema da inspiração na Antiguidade: Nietzsche parece pender entre o modelo psicofisiológico de Aristóteles e o modelo divino de Platão, como se ele reencenasse nesses dois momentos a candente polêmica outrora travada entre os dois maiores vultos do classicismo grego. Para que isso fique claro, cumpre esmiuçar mais detidamente esses problemas.

\section{Inspiração no Humano, demasiado humano: a versão secular da inspiração}

Como se sabe, o projeto do Humano, demasiado bumano, é precisamente o de ver coisas humanas ali onde a maioria das pessoas encontra coisas ideais (NIETZSCHE, 2002b, p.322). O livro pertence à escola da suspeita (Schule des Verdachts) e nutre desconfiança profunda diante da moral. Nele, os falsos ídolos da filosofia devem ser reduzidos, através de um combate iluminista ao estilo de Voltaire (a quem o livro é dedicado), à sua reles origem humana, 
libertando assim os espíritos outrora engabelados por superstições. No caso da inspiração, isso se dá de modo exemplar. $\mathrm{Na}$ parte que trata da alma dos artistas e escritores, Nietzsche escreve dois aforismos que pretendem eliminar o caráter fantástico e sagrado com que normalmente se compreendia a origem da obra de arte. Ele afirma que os próprios artistas possuem interesse em fazer com que o público acredite em intuições súbitas (plötz̧liche Eingebungen), tal como se a ideia de uma obra ou mesmo o pensamento fundamental (Grundgedanke) de uma filosofia lhes caíssem do céu como uma graça (Gnadenschein). Entretanto, o que de fato ocorre é um processo de ordem psicológica. A imaginação (Phantasie) do artista e do pensador produz continuamente (fortwährend) coisas boas, medianas e medíocres, e sua faculdade de juízo (Urteilskraft) então aprimora, cultiva, seleciona e bane parte desse material, como se pode perceber a partir dos cadernos de notas de Beethoven. Para Nietzsche, o grande compositor alemão - uma das personificações por antonomásia do gênio - foi na verdade um infatigável trabalhador. Mesmo a improvisação, que parece falar a favor da inspiração súbita, nada mais é do que um processo psicológico em que o artista confia em sua memória imitativa (nachbildende Erinnerung), a qual então separa por conta própria o material a ser trabalhado e depois o apresenta ao artista. Ela é inferior, por conseguinte, ao ato de julgar, descobrir e rejeitar que é realizado séria e incansavelmente pelos pensamentos artísticos (Kunstgedanken) quando metodicamente trabalhados.

155. A crença na inspiração. Os artistas têm interesse em que se creia nas intuições repentinas, nas chamadas inspirações; como se a ideia da obra de arte, do poema, o pensamento fundamental de uma filosofia, caísse do céu como um raio de graça. $\mathrm{Na}$ verdade, a fantasia do bom artista ou pensador produz constantemente, sejam coisas boas, medíocres ou ruins, mas o seu julgamento, altamente aguçado e exercitado, rejeita, seleciona, combina; como vemos hoje nas anotações de Beethoven, que aos poucos juntou as mais esplêndidas melodias e de certo modo as retirou de múltiplos esboços. Quem separa menos rigorosamente e confia de bom grado na memória imitativa pode se tornar, em certas condições, um grande improvisador; mas a improvisação artística se encontra muito abaixo do pensamento artístico selecionado com seriedade e empenho. Todos os grandes foram grandes trabalhadores, incansáveis não apenas no inventar, mas também no rejeitar, eleger, remodelar e ordenar (NIETZSCHE, 2005, p.111).

Em verdade, como Nietzsche comenta no próximo aforismo, o ato de improvisar e o ato de escrever ou pintar com fluência decorrem de um acúmulo de energia da faculdade de produção (Productionskraft) que, uma vez liberada em súbita efusão (plötz̧licher Erguss), dá a impressão de que a obra foi realizada sem nenhum esforço prévio, como se fora um milagre (Wunder). Esta é a ilusão (Täuschung) relativa à inspiração que os próprios artistas têm interesse excessivo em manter: não se trata de um conteúdo alheio às suas faculdades 
psicológicas que simplesmente cai do céu, mas do acúmulo do capital humano que, depois, vem novamente à tona. Embora Nietzsche não utilize aqui a palavra "inconsciente", não seria totalmente errôneo supor que se trata de um fenômeno desse jaez 4 . A mesma coisa acontece, segundo ele, no caso da virtude, do vício e da bondade: não há nenhuma graça ou maldição que nos fazem ser virtuosos ou maus, mas apenas o armazenamento de energia que depois flui em abundância, como se abríssemos as comportas de uma represa psicológica.

156. Ainda a inspiraşão. Quando a energia produtiva foi represada durante um certo tempo e impedida de fluir por algum obstáculo, ocorre enfim uma súbita efusão, como se houvesse uma inspiração imediata sem trabalho interior precedente, ou seja, um milagre. Isso constitui a notória ilusão que todos os artistas, como disse, têm interesse um pouco excessivo em manter. O capital apenas se acumulou, não caiu do céu. Aliás, há uma inspiração aparente desse tipo também em outros domínios, como por exemplo, no da bondade, da virtude, do vício (NIETZSCHE, 2005, p.111).

Todos esses comentários salientam o lado humano da inspiração e sua ligação com nossas faculdades psicofisiológicas. No lugar dos deuses, da graça, do milagre e da passividade extática do artista, apanágios universalmente atribuídos ao gênio, são colocados fenômenos como a energia produtiva, a memória, o trabalho consciente, o gosto, a faculdade de julgar etc. Esta perspectiva lembra em muitos sentidos o modelo de inspiração aristotélico, que também ataca esse problema a partir de um vocabulário psicofisiológico e mesmo patológico, ademais de frisar o lado técnico da poesia e sua estreita ligação com a racionalidade, excluindo, portanto, a intervenção divina. Para Aristóteles, a origem da poesia não depende das Musas, mas de duas causas naturais: nossa propensão inata à imitação e o prazer auferido nela.

Ao que parece, duas causas (aitial), e ambas naturais (physikaì), geraram a poesia. O imitar (mimeîsthal) é congênito no homem (e nisso difere dos outros viventes, pois, de todos, ele é o mais imitador, e, por imitação aprende as primeiras noções, e os homens se comprazem no imitado (Po. 1448b4-9, trad. modificada) ${ }^{5}$.

As Musas não são mencionadas sequer uma vez ao longo da Poética e a própria teologia de Aristóteles, com seu Dieu des philosophes et des savants que

\footnotetext{
${ }^{4}$ Sabe-se como Freud tentou evitar, de forma reiterada, o contato com a obra de Nietzsche, por temer justamente a parecença de suas ideias. Neste caso em específico, sua análise da melancolia e da mania relembram não apenas o que Nietzsche diz acerca da economia da psique, como também o que se diz no Problema XXX de Aristóteles sobre a relação entre álcool, loucura e melancolia, como reconhecido pelos estudiosos. FREUD, 2011, p.72-73; KEHL, 2011, p.22-23.

5 Note-se a maneira como 0 texto está redigido: com uma ênfase na naturalidade das causas mencionadas, retomada pela conjunção kaí, que deve eliminar qualquer ambiguidade acerca da origem da poesia.
} 
nada mais faz do que contemplar o próprio pensamento (nóesis noéseōs) (E.N. 1178b7-18; Metaph. 1074b15-35) ${ }^{6}$, torna absurda a crença nelas, pois parece banir a possibilidade de uma intervenção direta dos deuses no mundo sublunar7. Em outros textos, Aristóteles explica a composição de poemas através da teoria dos quatro humores - uma das maiores conquistas da medicina hipocrática de então - e recorre a fenômenos de ordem física e patológica, como a ingestão de vinho, o êxtase, a loucura e a melancolia, a fim de reduzir a inspiração a um estado psicofisiológico dos poetas (Probl. 954a2127) ${ }^{8}$. Para ele, a mistura (krâsis) de humores da natureza dos melancólicos é perfeita para a criação poética, já que faz deles pessoas altamente mutáveis (metabletitikoi) e capazes de associar ideias as mais diversas em uma mesma imagem. Pela primeira razão, eles desenvolvem um olhar empático e conseguem imitar diversas personagens e assumir seus caracteres; pela segunda, realizam com excelência o critério aristotélico da boa poesia: a criação de metáforas 9 . A única menção da loucura, na Poética, é também explicada através de conceitos oriundos da medicina. Os poetas considerados loucos pela opinião comum são, na verdade, pessoas cuja compleição psicofisiológica (phýsis) os leva a sair momentaneamente de si para imitar caracteres e imaginar ações (práxeis) possíveis segundo a verossimilhança (eikós) e a necessidade (anánkè). Ao contrário do que será defendido por Platão, sua loucura não é divina; antes, trata-se de um arroubo momentâneo que decorre da própria natureza dos poetas:

Deve também reproduzir [por si mesmo], tanto quanto possível, o gesto [das personagens]. Mais persuasivos, com efeito, são [os poetas] que, a partir da sua própria natureza (apò tês autês phýseōs), vivem as mesmas paixões (en toîs páthesin) [das personagens]; e por isso, o que está violentamente agitado excita nos outros a mesma agitação, e o irado, a mesma ira. Eis por que poetar é conforme seres naturalmente bem dotados/talentosos (euphyoûs) ou ensandecidos (manikồ); destes, os primeiros são de feitio plasmável (eúplastoi), e os outros são delirantes (ekstatikoi) (Po.1455a29-34 trad. modificada).

Ademais, no próprio título de sua obra - téchnē poietikè - estampa-se a negação das Musas e da inspiração: a poesia é uma téchnē, não uma graça divina

\footnotetext{
6 Um "monoteísmo abstrato", na clássica formulação de Zeller (1893, p.191).

7 Há controvérsias sobre isso. As passagens da Ética a Nicômaco e do livro lambda da Metafísica sugerem fortemente, todavia, que qualquer tipo de atividade terrena ou diferente da contemplação é indigna dos deuses. Confira-se a discussão: NORMAN, 1979.

8 Essa perspectiva é discutida no famoso Problema XXX, o qual, apesar de não ter sido diretamente escrito por Aristóteles, expressa com grande fidelidade as ideias do filósofo. Para Flashar e para Pigeaud, não há dúvidas sobre a origem aristotélica do texto, o qual teria, aliás, contribuído positivamente com a medicina da época. FLASHAR, 1956; PIGEAUD, 1998, p.17; p.58.

9 Sobre a relação entre melancolia, associação de imagens e pensamento metafórico, confira-se 0 pequeno tratado natural sobre a profecia nos sonhos: Div. Somn. 464a32-b4.
} 
(theîa moîra $)^{10}$. Por esse motivo, ela depende de uma concepção universal (bypólēpsis kathólou) haurida a partir de uma multiplicidade de conhecimentos empíricos, ou seja, um conhecimento de causas (aitíai) que pode ser ensinado (dýnasthai didáskein) e aprendido por qualquer pessoa ${ }^{11}$. Ao invés de receber seus poemas das Musas, os poetas contêm em sua alma, como causas produtivas do poema, uma forma (eîdos) de sua futura criação, forma essa que eles reproduzem e aperfeiçoam a cada vez que compõem (Metaph. 1032b). Eles desenvolvem assim certa habilidade produtiva (béxis poiètikế), como ensina a Ética a Nicômaco, que vem acompanhada por um discurso verdadeiro (metà lógous alêthoûs) acerca de como gerar determinado produto ${ }^{12}$. Tal como o artesão que fabrica uma mesa, o poeta domina certo raciocínio (lógos) e uma série de concepções (bypólepseis) que o ensinam como criar, por exemplo, uma personagem tímida ou raivosa. Uma vez que isso possa ser ensinado e aperfeiçoado com o emprego da racionalidade própria da técnica, parece que Aristóteles concordaria com a ideia nietzschiana de que Beethoven foi um grande trabalhador.

É difícil dizer o quanto Nietzsche era consciente de que, ao frisar o lado humano da inspiração, estava a retomar vários traços do modelo aristotélico. Sabemos que ele emprestou na biblioteca o livro de Jacob Bernays sobre a catarse em Aristóteles, quando escrevia o Nascimento da Tragédia (CHAVES, 2012, p.13, n.12). É provável que a ênfase de Bernays no aspecto médico do conceito aristotélico - ênfase que um dos mais íntimos amigos e defensores de Nietzsche naquela época, Erwin Rohde, também endossava tenha deixado alguma marca no jovem filólogo, marca essa que pode ser vista não apenas aqui, como também nas ideias de instinto primaveril (Früblingstrieb) e de embriaguez dionisíaca (Rausch) já presentes em suas preleções sobre a visão dionisíaca de mundo (NIETZSCHE, 1988b). Conhecedor que era de Homero e Hesíodo, ele deve ter percebido que Aristóteles partia da divisão das ciências e das artes, bem como dos recentes conhecimentos da medicina e da psicologia empírica, para propor algo novo no domínio da teoria estética, algo que já havia aparecido timidamente, porém, nos rompantes do movimento sofista, responsável pelas primeiras tentativas de secularizar a palavra poética (DETIENNE, 1988). A significativa ausência das Musas em um filósofo cujo método preconiza, como uma de suas etapas fundamentais, a discussão das éndoxa de seus adversários, pois, deveria deixar atento um helenista arguto

10 Sobre isso, a decisiva conclusão de Halliwell: "Given the use made by Plato of the idea of inspiration, there can be no doubt that Aristotle's virtual silence on this score is meant to be eloquent" (1998, p.91).

${ }_{11}$ Para a análise da técnica, confira-se o livro Alfa da Metafísica.

12 Confira-se o livro VI da Ética a Nicômaco. 
como Nietzsche. Não se pode possível saber em definitivo, contudo, se ele pensava ou não em Aristóteles ao propor a desmitificação da inspiração por meio de uma reductio ad physiologiam.

\section{Inspiração no Ecce Homo: o modelo da revelação divina}

No segundo modelo, porém, Nietzsche menciona expressis verbis os antigos, apesar de nada dizer de Platão.

Ao comentar como compôs o Zaratustra, ele cita a experiência dos poetas de eras mais fortes, que teriam vivido milênios atrás, e explica o que seria sua experiência da inspiração. Com o resto de superstição que se permite, ele afirma que o poeta é a pura encarnação, o puro porta-voz (Mundstück) e meio (Medium) de potências superiores (übermächtige Gewalten). A mais exata descrição do fenômeno encontra-se no conceito de revelação (Offenbarung), no sentido de que, subitamente e com indizível certeza (unsägliche Sicherheit) e sutileza (Feinheit), algo se torna visível e audível. O poeta então escuta algo que vem de fora, mas não procura conscientemente por isso; ele apenas recebe um pensamento que o atinge como se fosse um relâmpago, sem se perguntar quem é que lho doa. A própria forma do pensamento já vem pronta e exime o poeta de fazer escolhas; ao contrário, ele sabe com certeza, sem hesitação, que deve empregar esta ou aquela palavra, este ou aquele metro. $\mathrm{O}$ paciente trabalho de julgamento antes acentuado torna-se agora um processo impessoal e repentino. Trata-se de um rapto (Entrü̈kekng) que descamba em uma corrente de lágrimas (Tränenstrom), diante da qual o passo ora se acelera, ora se torna lento, sem nenhuma arbitrariedade. Em um completo estar fora de si (Ausser-sich-sein) que mantém a consciência distinta de um sem-número de finos estremecimentos até os dedos do pé, irrompe uma profundidade de alegria (Glückstiefe) em que mesmo as coisas mais dolorosas (das Schmerzlichste) e sombrias (das Düsterste) não agem como contrários, mas como colorações necessárias dentro de tal excesso de luz (Lichtüberfluss). No escritor desperta então um instinto de relações rítmicas que alcança o mais longínquo espaço de formas que ele pode vir a utilizar. Na verdade, o alcance e a necessidade de um amplo ritmo (weitgespannter Rhytmus) são a medida para a violência da inspiração: uma espécie de balanço (Ausgleich) contra sua pressão e tensão.

Tem alguém, no final do século XIX, um conceito claro do que os poetas de épocas fortes chamavam inspiração? Caso contrário, quero aqui descrevê-lo. Com o mínimo resto de superstição em si, dificilmente alguém saberia, de facto, rejeitar a ideia de ser apenas a encarnação, simplesmente o porta-vOz, o medium de poderes superiores. $\mathrm{O}$ conceito de revelação, no sentido de que subitamente, com uma segurança e uma delicadeza imensas, algo se torna visível, audível, algo que nos abala e nos transtorna no mais profundo de nós mesmos, descreve simplesmente a situação real. Ouve-se, não se busca; aceita-se, não se pergunta 
quem aí dá; como um relâmpago, brilha um pensamento, com necessidade, na forma sem hesitações - jamais fiz uma escolha. Um arroubo cuja tensão ingente se atenua numa torrente de lágrimas, em que o passo, involuntariamente, ora se torna tempestuoso, ora lento; um perfeito estar fora-de-si com a consciência mais distinta de um sem número de finos tremores e exsudações até às pontas dos pés; um abismo de felicidade, em que o extremo de sofrimento e de melancolia não atua como contraste, mas como condicionado, como exigido, como uma cor necessária no meio de um tal excesso de luz; um instinto de relações rítmicas, que abrange amplos espaços de formas - a extensão, a necessidade de um ritmo largo constitui quase a medida do poder da inspiração, uma espécie de compensação para o seu constrangimento e a sua tensão ... (NIETZSCHE, 2008, p.77-78).

Em seguida, Nietzsche menciona novamente a necessidade e a divindade do fenômeno, afirmando que "tudo ocorre involuntariamente (unfreiwillig), no mais alto grau, mas como que em uma tempestade de sentimento de liberdade (Freiheitsgefüht), de incondicionalidade (Unbedingstsein), de poder (Macht) e divindade (Göttlichkeit)". A participação dos deuses é finalmente evocada, ainda que na forma genérica de um substantivo abstrato. O mais notável em todo o processo é, porém, justamente essa falta de arbitrariedade das imagens (Bilder) e símiles (Gleichnisse): o poeta perde a noção da diferença entre elas, pois tudo se lhe oferece através da mais simples expressão (einfachster Ausdruck). Relembrando o Zaratustra, Nietzsche afirma ter a impressão de que as próprias coisas se adiantam e oferecem para tornar-se alegorias e metáforas: o poeta como que cavalga em cada símile em direção a uma nova verdade, e todo o ser (alles Sein) quer tornar-se palavra.

Tudo acontece de um modo involuntário até ao mais alto grau, como num ciclone do sentimento de liberdade, do ser-incondicionado, de poder, de divindade... O mais notável é o carácter compulsivo da imagem, da metáfora; deixa de se ter um conceito do que é uma imagem ou uma metáfora, tudo se oferece como a expressão mais imediata, mais correta, mais simples. De facto, para lembrar uma palavra de Zaratustra, parece que as coisas surgem por si mesmas e se proporcionam à metáfora (- "Todas as coisas aqui acorrem amorosamente ao teu discurso e te adulam: querem, com efeito, cavalgar sobre as tuas costas. Em cada metáfora, galgas tu aqui para cada verdade. Para ti se abrem aqui palavras de todo o ser e sacrários da palavra; todo o ser pretende aqui tornar-se palavra, todo o devir quer de ti aprender a falar -”). Eis a minha experiência da inspiração; não duvido de que é necessário recuar milénios para encontrar alguém que me possa dizer: "E também a minha" (NIETZSCHE, 2008, p. 77-78).

Como dito, embora seja difícil saber se Nietzsche era consciente de que estava em dívida para com o modelo platônico de inspiração, sua menção dos poetas de eras antigas torna indubitável que ele se refere à Antiguidade. E, ali, Platão é o primeiro filósofo a oferecer explicação pormenorizada e filosófica de um fenômeno que já fora ressaltado por Homero e Hesíodo. O modelo que ele elabora em diálogos como o Íon, o Fedro, a Apologia e o Mênon é 
atuante em todas as descrições posteriores da inspiração; e é precisamente contra esse modelo que Aristóteles escreve sua Poética ${ }^{13}$.

No caso de Nietzsche, é possível rastrear vários vestígios de Platão. Em primeiro lugar, Platão enfatiza a completa passividade do poeta e do rapsodo - a metáfora da corrente magnética de inspiração permite deduzir, como se sabe, que a teoria do Íon (535e7-a3) se aplique a ambos - bem como sua ausência de escolhas: Íon não é capaz de recitar os poemas de qualquer poeta, como alguém que domina uma técnica poética poderia fazer, mas vê-se constrangido a falar apenas de Homero. Quando pensa neste poeta, sente-se desperto e as palavras fluem em completa abundância (euporía) de sua boca; quando se trata de ouro vate, porém, cai em aporia (aporeîn) e pega no sono (nystáżein).

Sócrates [...]. E a causa disto - pela qual tu me perguntas - e em função da qual tu, acerca de Homero, és desembaraçado (eúporos), mas acerca dos outros não, é que não é em virtude de técnica, mas de uma concessão divina (theîa moîra), que és terrivelmente hábil em louvar Homero (Ion. 536d1-3, trad. modificada).

Isso demonstra como ele é um instrumento passivo ou um medium ante a eleição das Musas. A poesia não é, portanto, algo de humano ou racional, que pode ser despertado conforme o bel-prazer do poeta, mas uma graça divina (thêia moîra) cuja manifestação depende do capricho dos deuses. A historieta sobre Tínico, contada ao longo do diálogo, comprova esse fato sob outro prisma. Segundo ela, Tínico tentara compor poesia em diversas ocasiões, mas fora sempre malsucedido, justamente porque a criação artística não dependia de seu arbítrio. Apenas quando as Musas decidiram agraciá-lo foi que ele, de súbito, pode dar à luz um dos mais belos poemas. Esse poema apareceu-lhe como um "achado das Musas", isto é, como algo pronto e sem hesitação, que antecipa o que Nietzsche escreve sobre a ausência de escolhas e a necessidade (Unfreiwilligkeit) experimentadas pelo poeta.

A maior demonstração dessa afirmação é Tínico de Calcídia, o qual não fez
nenhum outro poema que fosse digno de ser lembrado, exceto o peã que todos
cantam, talvez o mais belo poema lírico de todos, simplesmente, como ele
mesmo diz, "um achado das Musas". Nele, portanto, definitivamente, o deus
nos mostra, para que não duvidemos, que não são humanos (ouk anthrốpina)
estes belos poemas, nem de homens, mas divinos e de deuses (allà theîa kai
theōn), e os poetas não são nada além de intérpretes dos deuses, possuídos por
aquele que possui cada um. Demonstrando isso, o deus, intencionalmente,

${ }^{13}$ Sobre a polêmica aristotélica com a doutrina platônica da inspiração, que se reflete especialmente no trecho sobre a loucura poética acima citado, conferir os comentários clássicos de GUDEMAN (1934, p.307-309), ELSE (1957, p.491-501) e LUCAS (1968, p.177-179). Para a posição contrária, que vê a continuidade entre os dois autores, conferir BÜTTNER (2000, p.273-314) e SCHMITT (2011, p.546-553). 
através do mais medíocre poeta, cantou o mais belo poema lírico. Ou não te parece que falo a verdade, Íon? (Ion. 534d4-5352).

Além disso, o poeta e o rapsodo platônico começam seu processo de composição da récita depois de embarcar no ritmo e na harmonia. Tal como Nietzsche, eles ficam inteiramente fora de si e são tomados pela linguagem, como se participassem de um cortejo de bacantes. Suas faculdades psicológicas são impiedosamente negadas: eles perdem sua razão costumeira (ékphrōn) e são raptados pelo ritmo. Ao contrário do que ocorria no modelo aristotélico e no Humano, demasiado bumano, agora é precisamente a negação da racionalidade que torna o poeta apto a receber a inspiração e a compor.

Sócrates. [...] Pois todos os poetas de versos épicos, os bons, não em virtude de técnica, mas estando entusiasmados (éntheor) e possuídos (katechómenor), é que dizem todos aqueles belos poemas, e os poetas líricos, os bons, do mesmo modo. Assim como os coribantes não dançam freneticamente estando em seu juízo (ouk émphrones) assim também os poetas líricos não fazem aquelas belas melodias estando em seu juízo, mas, quando eles embarcam na harmonia e no ritmo, eles se tornam bacantes e possuídos; como as bacantes retiram dos rios mel e leite quando estão possuídas, mas não estando em seu juízo, também a alma dos poetas trabalham assim, como eles mesmos dizem. Pois os poetas nos dizem - não é? - que, colhendo de fontes o mel corrente de certos jardins e vales das Musas, eles nos trazem as melodias; como as abelhas, também eles assim voam. E dizem a verdade. Pois coisa leve é o poeta, e alada e sacra (bierón), e incapaz de fazer poemas antes que se tenha tornado entusiasmado e ficado fora de seu juízo (ékphrōn) e o senso (nô̂s) não esteja mais nele. Enquanto mantiver esse bem, o senso, todo o homem é incapaz de fazer poemas e de cantar oráculos (Ion. 533e5-534b7).

Na linguagem do Fedro - diálogo que, junto com o Mênon e a Apologia, mantém unidade doutrinal cerrada com Íon no que tange ao tema da poesia como concessão divina (theîa moîra) - o poeta é tomado por uma loucura sagrada que significa uma libertação divina (theîa exallagế) de seus hábitos cotidianos. É nisso que se diferencia a loucura sagrada da humana, concebida por Platão como simples doença (nósos) (Phdr. 244a3-8).

A terceira manifestação de possessão (katōkokeée e de delírio (manía) provém das Musas: quando se apodera de uma alma delicada e sem mácula, desperta-a, deixa-a delirante e lhe inspira odes e outras modalidades de poesia que, celebrando os numerosos feitos do passado, servem de educar seus descendentes. Mas, quem se apresenta às portas da poesia sem estar atacado do delírio (áneu manias) das Musas, convencido de que apenas com o auxílio da técnica (ek téchnès) chegará a ser poeta de valor, revela-se, só por isso, de natureza espúria, vindo a eclipsar-se sua poesia, a do indivíduo equilibrado (tồ sōphronûntos), pela dos poetas tomados do delírio (mainoménōn) (Phdr. 245a1-8).

De novo, os poetas não podem escolher o tema de sua composição, nem exercer qualquer tipo de trabalho intelectivo ou de juízo estético: é a 
própria divindade quem lhes comunica a futura obra. O poeta se revela o porta-voz de potências superiores que se doam à revelia de sua vontade.

\section{Conclusão}

Os elementos realçados por Nietzsche estão presentes, em suma, no modelo de Platão. Mesmo que Nietzsche tivesse em mente a experiência da tradição épica de Homero e Hesíodo, cuja poética implícita antecipa em pontos fundamentais a análise filosófica de Platão ${ }^{14}$, não é de todo precipitado imaginar que a leitura dos Diálogos reverberasse agora em sua mente. Em especial, a leitura do Fedro - obra sobre a qual dedicou algumas de suas aulas pode ter sido inconscientemente aludida, dado que este diálogo seja escrito conforme o paradigma do Íon. Aliás, Nietzsche fora também ávido leitor de Goethe, o qual escreveu um pequeno e, no interior da cultura alemã, influente ensaio sobre o Íon, a despeito de não haver captado a mensagem de Platão. Este fato pode ter pesado na descrição nietzschiana da inspiração. Em todo o caso, para o leitor familiarizado com a discussão da inspiração na Antiguidade, resulta claro que Nietzsche oscila nessas duas ocasiões entre Platão e Aristóteles.

Mais do que ensejar uma reflexão sobre as influências dos autores clássicos na obra de Nietzsche, esse fato abre espaço para a questão da transmissão da filosofia antiga e, de resto, para a questão da transmissão da filosofia como um todo. Sobre isso, gostaria de comentar algumas reflexões de Pierre Hadot, intelectual sobremaneira atento aos retornos do pensamento antigo nas fases posteriores da história. Ao invés de indagar-se sobre uma filiação consciente ou explícita da parte dos autores modernos em relação aos antigos, como é costumeiro nos estudos de epigonalidade, Hadot propõe a exploração do conceito retórico de tópos como uma forma de entender tais relações. Para ele, grande parte das ideias modernas sobre assuntos como autoconhecimento, Deus, natureza etc., são retomadas amiúde inconscientes de formulações teóricas que remontam à Antiguidade. Essas ideias seriam reformuladas como os loci communes da retórica, valendo como argumentos ou motivos literários semiprontos que se prestam ao tratamento de diversos temas. O número de tais tópoi seria relativamente restrito, de modo que seu estudo exaustivo poderia fornecer amplo panorama sobre a tradição Ocidental e, especialmente, sobre as modificações modernas de conceitos antigos.

Nosso pensamento ocidental nutriu-se e ainda vive de um número relativamente restrito de fórmulas e metáforas extraídas das diversas tradições das quais emergiu. Existem, por exemplo, as máximas que convidam a certa

${ }^{14}$ Cf. ENGLER, 2016, cap.II. 
atitude interior, como o "conhece-te a ti mesmo", as que por muito tempo orientaram a maneira de ver a natureza: "a natureza não dá saltos", "a natureza se compraz com a diversidade". Há metáforas como "a força da verdade", “o mundo como livro" (que se prolonga, talvez, na concepção do código genético como um texto). Existem as fórmulas bíblicas, como "sou aquele que é", que marcaram profundamente a ideia de Deus. O ponto que eu gostaria fortemente de sublinhar é o seguinte: esses modelos pré-fabricados, dos quais acabo de dar alguns exemplos, foram conhecidos, no Renascimento e no mundo moderno, precisamente sob a forma que tinham na tradição helenística e romana e foram originalmente compreendidos, no Renascimento e no mundo moderno, no mesmo sentido que esses modelos de pensamento tinham na época greco-romana e notadamente no final da Antiguidade. Esses modelos, portanto, explicam ainda muitos aspectos de nosso pensamento contemporâneo e até, precisamente, os significados às vezes inesperados que ele dá à Antiguidade (HADOT, 2012, p.37).

Hadot continua dizendo que, se isso procede, então o modelo de operação das ciências humanas seria profundamente devedor da retórica antiga, uma ideia com a qual Roland Barthes concordava. Embora se trate de interessante tese, não há espaço para discuti-la aqui. A partir do que foi exposto, gostaria apenas de sugerir que a inspiração poética, nas duas formas descritas acima, possui lugar indisputável entre esses tópoi, tendo sido inúmeras vezes retomada para deslindar a natureza da obra de arte. Em sua versão divina, ela ressurgiu na obra de uma miríade de autores antigos e modernos, de Platão a Thomas Mann e Boris Pasternak, sem deixar incólumes os defensores da ideia de gênio (Kant, Schopenhauer, Hölderlin etc.). Em sua versão secular, ela reapareceu igualmente na em vários momentos da história, desde Horácio até os teóricos da psicanálise e da medicina do final do XIX ${ }^{15}$. O caso de Nietzsche mostra de modo exemplar como essas antigas ideias encontraram guarida na pena de um autor moderno e como a filosofia se reinventa a partir de bases antigas, por mais que muitos pensadores - inclusive o próprio Nietzsche ${ }^{16}$ - queiram arvorar-se absoluta originalidade.

15 Sobre essas teorias e a maneira como reduziam o gênio à constituição corpórea, confira-se o ensaio do poeta e médico alemão, Gottfried Benn: BENN, 1997.

${ }^{16}$ Sobre essa estratégia nem sempre justificada dos autores modernos, confira-se o estudo clássico de SCHMITT, 1990, que analisa o caso específico de Homero, tomado pelos modernos como sua contraparte extrema. Toda a obra desse eminente filólogo alemão visa retificar os juízos modernos feitos sobre os antigos. Sobre o caso de Platão, por exemplo, cf.: SCHMITT, 2011b; 2008. 


\section{Referências}

ARISTÓTELES. Poética. Tradução: Eudoro de Souza. $2^{a}$ ed. São Paulo: Ars Poetica, 1993. Texto grego baseado na edição de Les Belles Lettres, 1932.

. De Arte Poetica Liber. Recognovit brevique adnotatione critica instruxit Rudolfus Kassel. Oxford: Oxford University Press, 1965

Poetik. Mit Einleitung, Text und Adnotatio Critica, Exegetschem Kommentar, Kritischem Anhang und Indices Nominum, Rerum, Locorum von Alfred Gudeman. Berlin-Leipzig: Walter de Gruyter, 1934.

- Poetik. Übersetzt und erläutert von Arbogast Schmitt. Berlin: Akademie Verlag, GmbH, 2011. 1975. . Nichomachean Ethics. Transl. H. Rackham. Cambridge; London: Loeb, . Poetics. Introduction, Commentary and Appendixes by D.W. Lucas. Oxford: Clarendon Press, 1968.

. Metafisica. Vol. II. Trad. do grego: Giovanni Reale. Trad. do italiano: Marcelo Perine. São Paulo, Loyola, 2014. 1998. . O homem de gênio e a melancolia (Problema XXX). Rio de Janeiro: Aguilar, . "On prophecy in Sleep". In: On the soul. Parva Naturalia. On Breath. Translation: W. S. Hett. Cambridge; London: Loeb, 1957.

ARENDT, H. Entre o Passado e o Futuro. $4^{a}$ ed. São Paulo: Perspectiva, 1972.

BENN, G. Genie und Gesundheit. In: BENN, Gottfried. Essays und Reden. Frankfurt am Main: Fischer Taschenbuch Verlag, 1997, p. 105-111.

BÜTTNER, S. "Inspiration and Inspired Poets in Plato's Dialogues". In: DESTRÉE, P; HERRMANN, F.-G. Plato and the Poets. Boston: Brill, 2011, p.111-131.

- Die Literaturtheorie bei Platon und ibre anthropologische Begründung. Tübingen: A. Francke Verlag, 2000.

CARNAP, R. "A Superação da Metafísica pela Análise Lógica da Linguagem”. Tradução de William Steinle. In: Cognitio, São Paulo, v.10, n.2, p.293-309, jul./dez. 2009. 
CHAVES, E. "Filosofia e filologia, tragédia e catarse: sobre a presença de Aristóteles na formação do pensamento de Nietzsche”. In: AISTHE, vol. VI, n.9, p.1-18, 2012.

DETIENNE, M. Os Mestres da Verdade na Grécia Arcaica. Rio de Janeiro: Jorge Zahar, 1988.

ELSE, G. Plato and Aristotle on Poetry. Chapel Hill-London: The University of North Carolina Press, 1986.

. Aristotle's Poetics: The Argument. Leiden: Brill, 1957.

ENGLER, M. R. Secularização e Praticidade: a Poética de Aristóteles em sua relação com a teoria da arte grega e com a filosofia do trágico. Tese de Doutorado. Universidade Federal de Santa Catarina, 2016, cap. III.

FLASHAR, H. Die medizinischen Grundlagen der Lehre von der Wirkung der Dichtung in der griechischen Poetik. Franz Steiner Verlag, Hermes, 84 Bd., H 1 (1956), p.1248.

- Der Dialog Ion als Zeugnis platonischer Philosophie. Berlin: Akademie Verlag, 1958.

FREUD, S. Luto e Melancolia. São Paulo: Cosac Naify, 2011.

HADOT, P. Elogio da filosofia antiga. São Paulo: Loyola, 2012.

HALLIWELL, S. Aristotle's Poetics. Chicago: University of Chicago Press, 1998, p. 91.

HORÁCIO. Arte Poética. Edição bilíngue. Trad. Dante Trigali. São Paulo: Musa Editora, 1993.

JANAWAY, C. "Arts and Crafts in Plato and Colingwood". In: The American Society for Aesthetics: The Journal of Aesthetics and Art Criticism, v.50, n.1, p.45-54, 2012.

KANT, I. Kritik der Urteilskraft. Hamburg: Meiner, 2001.

KEHL, M. R. Melancolia e criação. In: FREUD, Sigmund. Luto e Melancolia. São Paulo: Cosac Naify, 2011.

MICHELINI, A. E. (ed.). Plato as Author: the Rhetoric of Philosophy. Leiden; Boston: Brill, 2003.

NIETZSCHE, F. W. Götzen-Dämmerung. In: Sämtliche Werke. Band 6. Deutscher Taschenbuch Verlag. München: de Gruyter, 2002.

Zur Genealogie der Moral. In: Sämtliche Werke. Band 5. Deutscher Taschenbuch Verlag. München: de Gruyter, 1999. 
. Die Philosophie im tragischen Zeitalter der Griechen.. In: Sämtliche Werke.

Band 1. Deutscher Taschenbuch Verlag. München: de Gruyter, 1988.

. Die dionysische Weltanschanung.. In: Sämtliche Werke. Band 1. Deutscher Taschenbuch Verlag. München: de Gruyter, 1988b.

. Ecce Homo. In: Sämtliche Werke. Band 6. München: Deutscher Taschenbuch Verlag GmbH e Co. KG, 2002b.

. Ecce Homo. Como se chega a ser o que se é. Trad: Artur Mourão. Covilhã: LuSofia Press, 2008.

. Humano, demasiado bumano. Trad. Paulo César de Souza. São Paulo: Companhia das Letras, 2005.

NORMAN, R. "Aristotle's Philosopher God". In: In: BARNES, Jonathan; SCHOFIELD, M.; SORABJI, R. (Ed). Articles on Aristotle. 4 Psychology and Aesthetics. London: Duckworth, 1979, p.93-103.

NUSSBAUM, M. A Fragilidade da Bondade: fortuna e ética na tragédia e na filosofia grega. São Paulo: Editora WMF Martins Fontes, 2009.

PIGEAUD, J. Apresentação. In: ARISTÓTELES. O homem de gênio e a melancolia (Problema XXX). Rio de Janeiro: Aguilar, 1998.

PLATÃO. Íon. Trad. Cláudio Oliveira. Belo Horizonte: Autêntica, 2011.

. Fedro. $2^{\mathrm{a}}$ ed. Trad. Carlos Alberto Nunes. Belém: EDUFPA, 2007.

. Platonis Opera. Tomus II (org. John Burnet) New York: Oxford University Press, First Published 1901.

. Platonis Opera. Tomus III (org. John Burnet) New York: Oxford University Press, First Published 1903.

SCHMITT, A. Selbständigkeit und Abhängigkeit menschlichen Handels bei Homer. Hermeneutische Untersuchungen zur Psychologie Homers. Stuttgart: Franz Steiner Verlag, 1990.

- Denken und Sein bei Platon und Descartes. Kritische Anmerkungen zur „Überwindung" der antiken Seinsphilosophie durch die moderne Philosophie des Subjekts. Heidelberg: Universitätsverlag, 2011b.

. Die Moderne und Platon. Stuttgart-Weimar: J. B. Metzer Verlag, 2008.

VERDENIUS, W. J. L'Ion de Platon. Brill: Mnemosyne, Third Series, vol.11, 1943, p.233-262.

. Platon e la Poesie. Brill: Mnemosyne, Third Series, vol.12, Fasc.2, 1944, p.118-150. 
WEINECK, S.-M. The abyss above. Philosophy and poetic madness in Plato, Hölderlin and Nietzsche. New York: State University of New York Press, 2002.

WOOLF, R. "The Self in Plato's Ion". In: Apeiron. A Journal for Ancient Philosophy and Science, vol.30, n.3, p.189-210, September, 1997.

ZELLER, E. Grundriss der Geschichte der griechischen Philosophie. Vierte Auflag. Leipzig: O. R Reisland, 1893.

E-mail: reusengler@gmail.com

Recebido: 02/02/2017

Aprovado: 04/05/2017 